Vol. 1, No. 3, 2019

\title{
RANCANG BANGUN PRESENSI PERKULIAHAN MENGGUNAKAN QRCODE (STUDI KASUS FAKULTAS SAINS DAN TEKNOLOGI UNIVERSITAS KANJURUHAN MALANG)
}

\author{
Mutrikatul Khoiriyah ${ }^{1}$, Hari Lugis Purwanto ${ }^{2}$, Yoyok Seby Dwanoko ${ }^{3}$ \\ Sistem Informasi, Universitas Kanjuruhan Malang ${ }^{1,2,3}$ \\ mutrikatul.khoiriyah@gmail.com¹, hari_lugis@unikama.ac.id², yoyokseby@unikama.ac.id ${ }^{3}$
}

\begin{abstract}
Abstrak. Rancang Bangun presensi perkuliahan ini dibuat, bertujuan untuk membangun sistem presensi perkuliahan yang telah ada di Fakultas Sains dan Teknologi. Fokus peneliti pada pengembangan ini adalah pada proses presensi perkuliahan didalam kelas. sitem yang digunakan masih menggunakan media kertas untuk melakukan presensi perkuliahan sehingga menimbulkan beberapa permasalahan pada mahasiswa dan dosen terkait absensi. maka untuk mengatasi permasalahan presensi yang ada di Fakultas Sains dan Teknologi ( FST), dibutuhkan sistem presensi dengan memanfaatkan Qrcode untuk membantu proses absensi pada perkuliahan agar lebih cepat dan efektif. Pada penelitian ini Qrcode merupakan teknologi yang di gunakan pada system Android. instrumen penelitian dilakukan dengan observasi dan wawancara. Hasil penelitian berdasarkan User Acceptance Test menunjukkan bahwa $83 \%$ responden menyatakan setuju bahwa dengan adanya aplikasi presensi perkululiahan menggunakan Qrcode ini dapat membantu dalam pelaksanaan kegiatan presensi perkuliahan agar lebih efektif dan fleksibel.
\end{abstract}

\section{PENDAHULUAN}

Kata Kunci: Presensi; Android; Qrcode

Presensi menjadi salah satu faktor yang penting di Universitas Kanjuruhan Malang karena presensi merupakan tanda hadir seseorang. Pada penelitian ini terletak di Fakultas Sains dan Teknologi. Sistem pengumpulan data hadir mahasiswa yang terjadi di Fakultas Sain dan Teknologi saat ini pada presensi perkuliahan berlangsung, umumnya masih menggunakan media kertas (paper based) untuk pencatatan kehadiran mahasiswa.

Media kertas ini mempunyai kelemahan yaitu dengan adanya penitipan absen yang dilakukan oleh mahasiswa, tidak bisa mengetahui berapa banyak mahasiswa yang terlambat setiap semesternya, tidak diketahuinya mahasiswa yang bolos (izin keluar kelas setelah itu tidak kembali), dosen tidak dapat merekap presensi dalam satu pertemuan, dan sering hilangnya absensi diakhir semester. Oleh karena itu, perlunya adanya pengembangan rancang bangun presensi perkuliahan menggunakan media selain kertas.(media elextronik atau digital).

Qrcode adalah sebuah kode matriks dalam bentuk dua dimensi yang dikembangkan oleh perusahaan Jepang Denso-Wave pada tahun 1994. Tujuan dari Qrcode ini adalah untuk menyampaikan informasi secara cepat dan juga mendapat tanggapan secara cepat. Pada awalnya Qrcode digunakan untuk pelacakan bagian kendaraan untuk manufacturing. Namun sekarang, telah digunakan untuk komersil yang ditujukan pada pengguna telepon seluler. [5].

Pada penelitian sebelumnya teknologi Qrcode sudah pernah diterapkan pada beberapa studi kasus yaitu:

Adapun jurnal rujukan yang telah berhasil sebaai referensi yaitu " berjudul Sistem absensi asisten dosen menggunakan Qrcode scanner berbasis android pada program studi sistem informasiUniversitas Muria Kudus" yang berhasil di uji. Perancangan yang dilakukan telah menghasilkan sebuah Sistem Absensi Asisten Dosen Menggunakan Qrcode Scanne berbasis Android yang dapat memproses absensi dan pengelolaan honor asisten dosen. Sistem Absensi Asisten Dosen Menggunakan Qrcode telah berhasil diterapkan pada universitas muria kudus terkait absensi asisten dosen [3]. Jurnal rujukan yang berjudul Smart presensi menggunakan Qrcode dengan enkripsi vigenere Cipher telah di uji coba dan berhasil diimplementasi pada integrasi Sistem Informasi Akademik (SIA) dapat menghubungkan data yang dikirim dari 
Sistem Absensi menggunakan Qrcode Scanner. Sistem yang dikembangkan dapat mempermudah dosen dalam proses absensi ujian tengah semester (UTS) ataupun Ujian Akhir Semester (UAS). dapat disimpulkan bahwa Qrcode mampu mengatasi permasalahan presensi yang ada di perusahaan atau organisasi. Karena Qrcode merupakan media yang digunakan dalam penyampaian informasi secara cepat dan mendapat respons yang cepat tanpa melakukan input secara manual dengan cara mengetik [4].

Berdasarkan permasalahan diatas, maka untuk mengatasi permasalahan yang ada di Fakultas Sains dan Teknologi (FST) terkait presensi tersebut dibutuhkan sistem presensi dengan memanfaatkan Qrcode untuk membantu proses presensi pada perkuliahan agar lebih cepat dan efektif. Pada penelitian ini Qrcode merupakan teknologi yang di gunakan pada system Android dengan tujuan untuk memudahkan Dosen dalam melalukan absensi, memudahkan mahasiswa dalam melakukan presensi perkuliahan, mengecek keluar masuknya mahasiswa, mengetahui mahasiswa yang terlambat per pertemuan, menghindari penitipan absensi bagi mahasiwa, menghindari rekap absensi bagi dosen, mahasiswa dan dosen dapat mengetahui pergantian jadwal perkuliahan (apabila dosen berhalangan masuk kelas pada hari sebelumnya).

Pada aplikasi Rancang Bangun Presensi Perkuliahan Menggunakan Qrcode ini, nantinya akan ada 2 system yang digunakan. Yaitu pada komputer dosen masing-masing yang berisi kode QR yang ditampilkan di layar LCD untuk mahasiswa melakukan presensi perkuliahan dengan scan Qrcode dan alat yang diletakkan didepan pintu kelas yang berisi kode QR untuk mahasiswa melakukan presensi perkuliahan sesuai jadwal yang telah dijadwalkan. Pada aplikasi ini hanya membahas seputar presensi perkuliahan.

\section{METODE PENELITIAN}

\section{A. Model Waterfall}

Model penelitian pengembangan yang digunakan dalam pengembangan ini menggunakan waterfall adalah suatu proses pengembangan perangkat lunak berurutan dimana kemajuan terus mengalir ke bawah seperti air terjun melewati tahap tahapanya. Inti dari model waterfall adalah pengerjaan dari suatu sistem dilakukan secara berurutan atau secara linier. Berikut adalah gambar model waterfall menurut [2]. Dapat dilihat pada gambar 1.

\section{Analisis Kebutuhan}

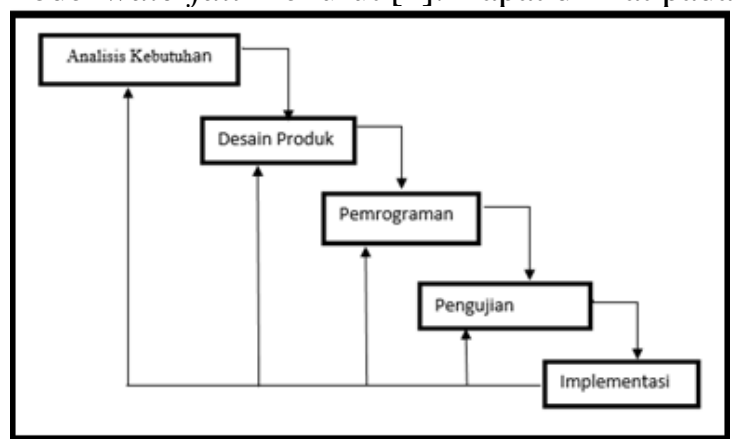

Gambar 1 Model Pengembangan Waterfall

Proses tahapan analisis kebutuhan, peneliti melakukan 2 (dua) tahapan untuk menunjang kebutuhan pengembangan yaitu melakukan (1) wawancara dan observasi untuk mendapatkan data dan fakta permasalahan (2) penyusunan aktor yang terlibat didalam sistem. Mengenai kebutuhan perangkat lunak yang akan digunakan untuk pengembangan sistem. Peniliti melakukan studi lapangan kepada Staf Kaprodi dan Biro Administrasi Akademik (BAA). Kebutuhan perangkat lunak dalam penelitian ini menggunakan PHP, Android, Adobe, Dreamwever CS6 dan Xampp, Browser gambar analisis kebutuhan dapat dilihat pada gambar 2. 


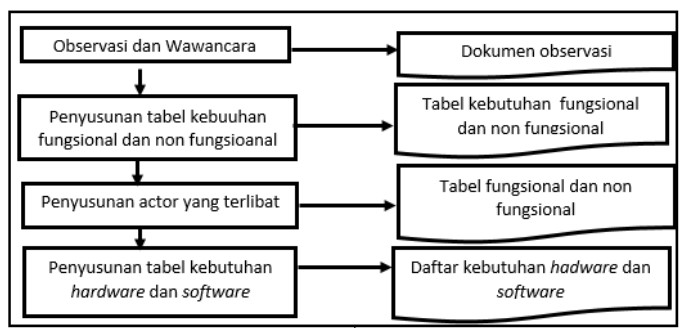

2. Desain Produk

Gambar 2 Analisis Kebutuhan

Pada desain produk ini dilakukan 2 tahapan yaitu:

a. Pembuatan desain program perangkat lunak yaitu pemodelan dan desain tampilan GUI.

b. Merancang desain sistem menggunakan UML diantaranya Use case, Sub use case, Activity diagram, Sequence diagram dan Class diagram untuk mempermudah proses pembuatan rancang bangun sistem.

3. Pemograman

Pada pemrograman ini, disesuaikan dengan desain produk yang sudah direncanakan, setelah itu dilakukan pemrograman atau disebut developmet. Software yang digunakan adalah Komodo IDE 9 dan Android Studion untuk memudahkan dalam melakukan proses pemrograman dan implementasi desain produk

4. Pengujian

Pada tahap ini dilakukan untuk menguji fungsional sistem presensi perkuliahan dan memastikan bahwa semua bagian sudah diuji. Sehingga didapatkan sebuah sistem yang layak digunakan oleh pengguna. Tahap uji pengguna dilakukan oleh dosen, mahasiswa, kaprodi dan administrator

5. Implementasi

Tahap implementasi ini meliputi implementasi program dan uji coba serta evaluasi system presensi perkuliahan yang bertujuan untuk mengetahui hasil dari kebutuhan fungsional sistem yang disusun dan dicocokan dengan hasil implementasi dalam bentuk Rangcang Bangun Sistem Informasi.

\section{HASIL DAN PEMBAHASAN}

A. Analisis Kebutuhan

Pada Analisis Kebutuhan peneliti melakukan observasi dan wawancara dengan mengajukan pertanyaan mengenai kebutuhan fungsional dan non fungsional yang akan dibutuhkan dalam sistem pengembangan presensi perkuliahan.

Kebutuhan funsional adalah kebutuhan yang berisi proses pada sistem, sedangkan kebutuhan non fungsional adalah kebutuhan yang menitik beratkan pada prilaku yang dimiliki sistem. Kebutuhan fungsional dapat dilihat pada tabel 1.

Tabel 1 Kebutuhan Fungsional

\begin{tabular}{ll}
\hline No & Deskripsi \\
\hline 1 & Merubah data presensi \\
2 & Memasukkan data dosen dan mahasiswa \\
3 & Mengetahui dosen dan mahasiswa yang terlambat \\
4 & Sistem dapat melihat jadwal perkuliahan dan menyediakan kode Qrcode \\
5 & Menghindari penitipan absensi bagi mahasiswa, dan rekapa absensi bagi \\
& Mesen \\
6 & Mengganti jadwal perkuliahan. \\
7 & Memonitoring presensi dosen riwayat presensi mahasiswa dan dosen \\
8 & Mengisi catatan mengajar dan melakukan scan paraf di akahir perkuliahan \\
10 & Memperbaharui profil apabila ada perubahan biodata. \\
\hline
\end{tabular}

Berikut adalah tabel kebutuhan non fungsional dapat dilihat pada tabel 2.

Tabel 2 Kebutuhan Non Fungsional 


\begin{tabular}{ll}
\hline No & Kebutuhan \\
\hline $\mathbf{1}$ & User Friendly \\
$\mathbf{2}$ & Sistem berjalan 24 jam kecuali dalam masa perbaikan \\
$\mathbf{3}$ & Berjalan di semua handphone android \\
\hline
\end{tabular}

\section{B. Desain Produk}

Pada tahap desain produk ini untuk Merancang desain sistem dengan menggunakan Unified Modeling Language (UML) dalam proses menggambarkan sistem dimulai dari pembuatan Use case Diagram Utama, Sub Use case, Activity, Sequence dan Class Diagram. agar lebih memudahkan dalam proses pembuatan produk. Dapat dilihat pada gambar 3 UseCase Diagram Utama.

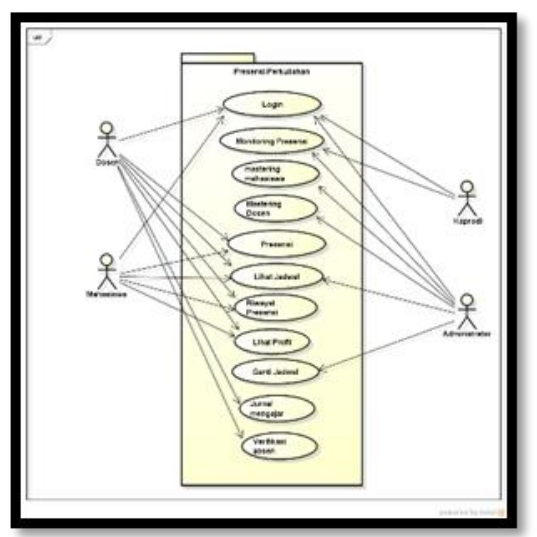

Gambar 3 UseCase Diagram Utama

Penjelasan usecase diagram utama sebagai berikut:

1. Login digunakan oleh user untuk masuk pada menu utama dengan cara memasukkan username dan password sesuai data user.

2. Monitoring Presensi digunakan oleh kaprodi untuk memonitoring absensi dosen.

3. Mastering mahasiswa digunakan oleh administrator untuk memastering data mahasiswa.

4. Mastering dosen digunakan oleh administrator untuk memastering data dosen.

5. Presensi digunakan oleh dosen dan mahasiswa untuk melakukan presensi pada saat perkuliahan berlangsung (scan qrcode)

6. Lihat jadwal dilakukan oleh dosen dan mahasiswa untuk melihat jadwal perkuliahan yang telah diambil. Dan dilakukan oleh admin untuk memperbaharuui jadwal perkuliahan.

7. Riwayat presensi dilakukan oleh dosen untuk melihat riwayat presensi mahasiswa, dan mahasiswa melihat riwayat presensi sendiri.

8. Lihat profil dilakukan oleh dosen dan mahasiswa untuk melihat profil.

9. Ganti jadwal dilakukan oleh admin untuk mengganti jadwal perkuliahan (apabila dosen berhalangan hadir).

10. Jurnal mengajar dilakukan oleh dosen untuk mengisi jurnal mengajar diakhir perkuliahan.

11. Verifikasi absen dilakukan oleh mahasiswa untuk melakukan verifikasi absensi diakhir perkuliahan (sebagai bukti bahwa dosen telah mengajar).

Dalam class diagram ini terdapat 17 class. Gambar dapat dilihat pada gambar 4. 


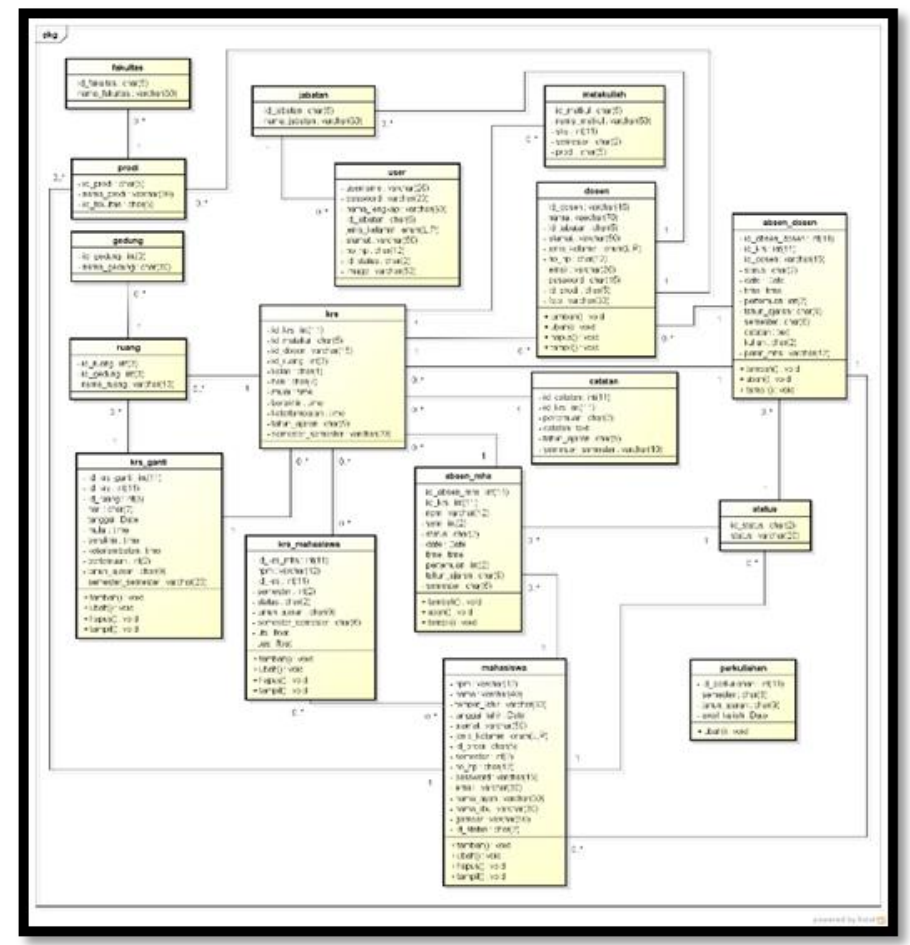

Gambar 4 Class Diagram

Penjelasan class diagram sebagai berikut: (1) absensi dosen untuk menyimpan data presensi dosen (2)absensi mahasiswa untuk menyimpan data presensi mahasiswa; (3)catatan untuk menyimpan data catatan pertemuan;(4) dosen untuk menyimpan data dosen; (5) fakultas untuk menyimpan data fakultas; (6) gedung untuk menyimpan data nama gedung ;(7) jabatan untuk menyimpan data jabatan; (8) krs untuk menyimpan data detail krs; (9) krs ganti untuk menyimpan data ganti jadwal; (10) krs mahasiswa untuk menyimpan data kers mahasiswa; (11) mahasiswa untuk menyimpan data mahasiswa; (12) matakuliah untuk menyimpan data matakuliah; (13) perkuliahan untuk menyimpan data perkuliahan; (14) prodi untuk menyimpan data prodi; (15) ruang untuk menyimpan data ruang; (16) status untuk menyimpan data status; (17) user untuk menyimpan data user;

Pembuatan desain GUI dalam setiap halaman sistem. yang digunakan untuk membuat desain Gui yaitu menggunakan aplikasi pencil. Berikut dapat dilihat pada gambar 5 Desain Gui.

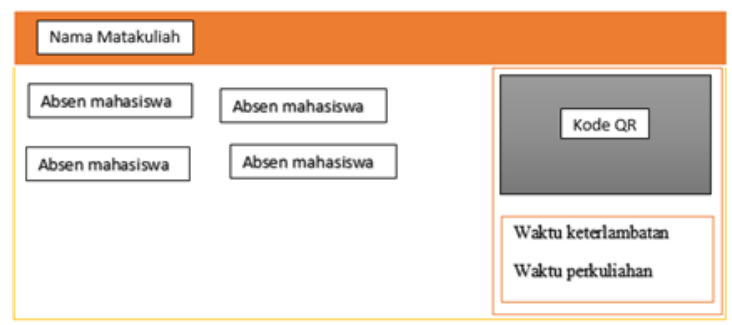

\section{Gambar 5 Desain Gui}

\section{Pemrograman}

Pada tahap pemroraman dilakukan proses pengkodean program sesuai dengan rancangan $U M L$ dan juga Desain Tampilan (user interface) yang telah dibuat. Pengkodean 
program rancang bangun presensi perkuliahan menggunakan Qrcode ini dibuat dengan menggunakan aplikasi Komodo IDE 9 dan android studio sebagai berikut. Dapat dilihat pada gambar 6 Tampilan Qrcode

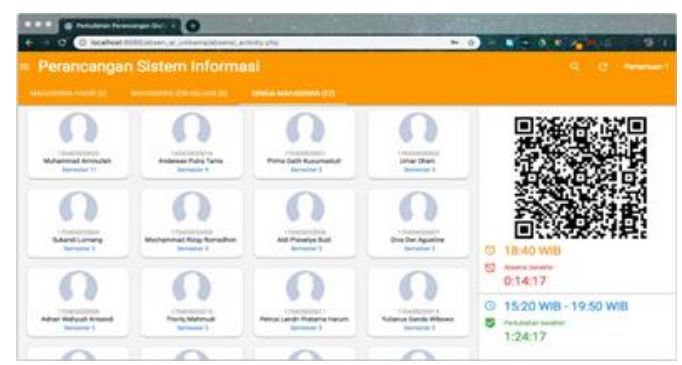

\section{Gambar 6 Tampilan Qrcode}

Tampilan scan presensi pada android dosen dan mahasiswa ketika akan melakukan presensi perkuliahan yang sedang berlangsung. dapat dilihat pada gambar 7 tampilan scan presensi.

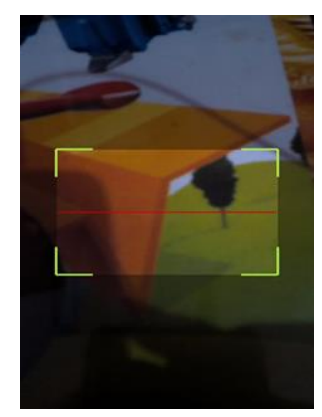

\section{Gambar 7 Tampilan Scan Presensi}

Tampilan dari mahasiswa hadir yang telah melakukan presensi perkuliahan pada android dosen. Dapat dilihat pada gambar 8 presensi mahasiswa hadir.

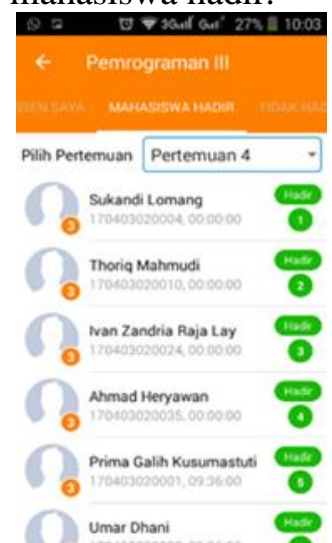

Gambar 8 Tampilan Presensi Mahasiswa Hadir

Tampilan mahasiswa yang tidak hadir dapat dilihat pada gamabar 9 Presensi Mahasiswa Tidak Hadir 


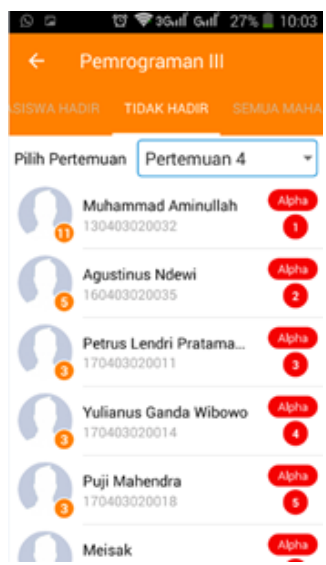

\section{Gambar 9 Tampilan Presensi Mahasiswa Tidak Hadir}

\section{Pengujian}

1. Tahap pengujian ini dilakukan dengan menggunakan Black Box pengujian dilakukan dengan mengetahui bahwa semuua objek dalam sistem dapat berjalan sesuai fungsi yang diberikan. Langkah pengujian ini dilakukan dengan menguji semua fungsi disetiap halaman. Hasil dari pengujian Black Box Testing dapat dilihat pada tabel 3 Uji Black Box Testing.

Tabel 3 Uji Black Box Testing

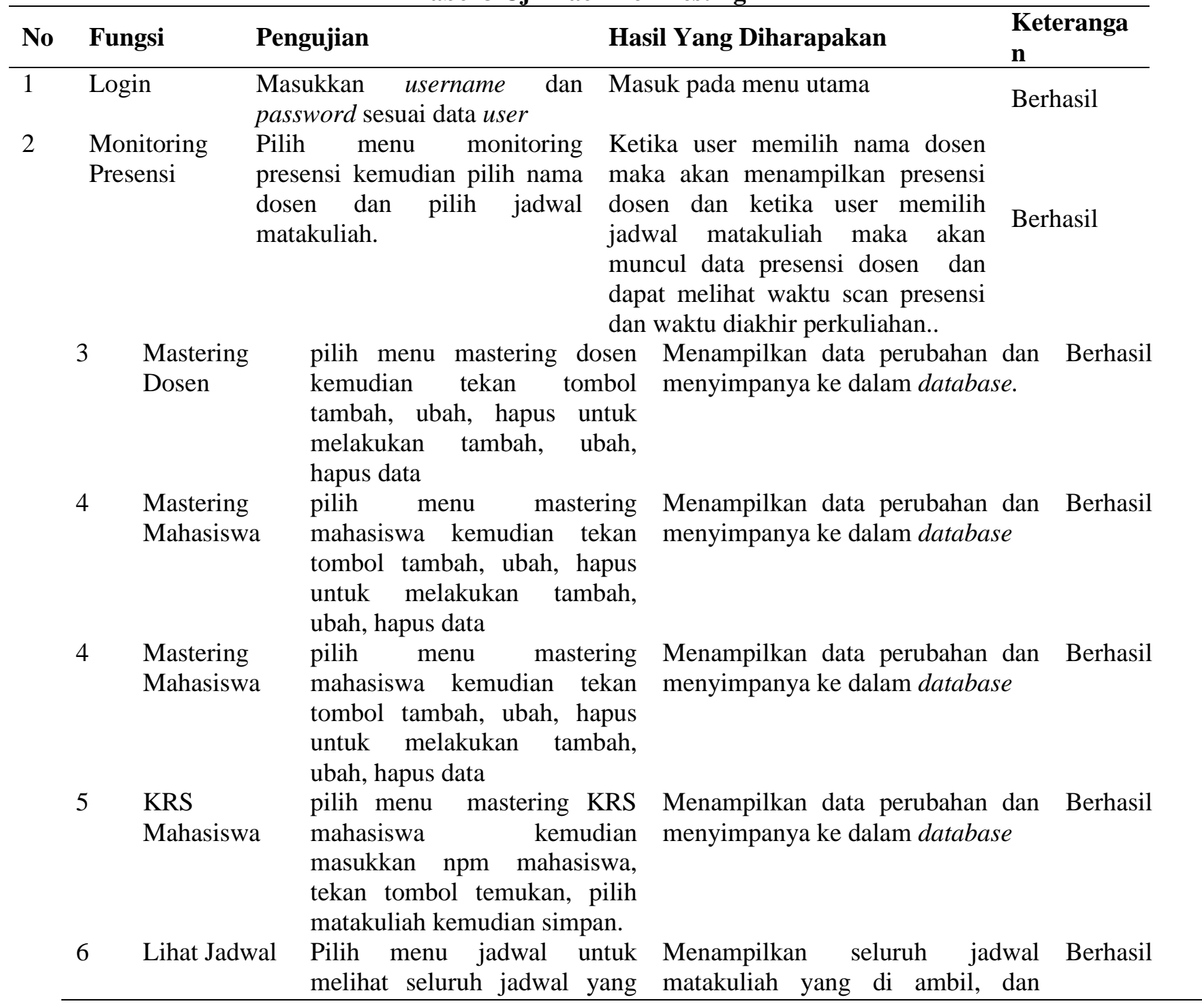




\begin{tabular}{|c|c|c|c|c|}
\hline & & diambil. & $\begin{array}{l}\text { untuk menampilkan jadwal pada } \\
\text { hari ini saja akan muncul di menu } \\
\text { hari ini. }\end{array}$ & \\
\hline 7 & Ganti Jadwal & $\begin{array}{l}\text { Melihat jadwal mata kuliah } \\
\text { pilih matakuliah yang akan } \\
\text { diganti kemudian isi form } \\
\text { ganti jadwal dan tekan button } \\
\text { simpan. }\end{array}$ & $\begin{array}{l}\text { Menampilkan jadwal matakuliah } \\
\text { dan menyimpan data pergantian } \\
\text { jadwal. }\end{array}$ & Berhasil \\
\hline 8 & $\begin{array}{l}\text { Riwayat } \\
\text { Presensi }\end{array}$ & $\begin{array}{l}\text { Melihat data riwayat presensi } \\
\text { dengan memilih menu absensi } \\
\text { kemudian pilih matakuliah dan } \\
\text { pilih pertemuan. }\end{array}$ & $\begin{array}{l}\text { Menampilkan data riwayat presensi } \\
\text { jika pengguna memilih pertemuan } \\
\text { dan matakuliah dimenu absensi. }\end{array}$ & Berhasil \\
\hline 9 & Lihat Profil & $\begin{array}{l}\text { Pilih menu profil untuk } \\
\text { melakukan pembaharuan } \\
\text { profil, dengan memasukkan } \\
\text { data yang akan diperbaharui } \\
\text { pada menuu edit lalu tekan } \\
\text { tombol simpan. }\end{array}$ & $\begin{array}{l}\text { Menampilkan data profil dan } \\
\text { menyimpan data yang sudah } \\
\text { diperbaharui. }\end{array}$ & Berhasil \\
\hline 10 & $\begin{array}{l}\text { Jurnal } \\
\text { Mengajar }\end{array}$ & $\begin{array}{l}\text { Pilih matakuliah yang sedang } \\
\text { berlangsung kemudian pilih } \\
\text { menu catatan dan mengisi } \\
\text { form catatan mengajar setelah } \\
\text { itu tekan tombol simpan. }\end{array}$ & $\begin{array}{l}\text { Menampilkan form catatan } \\
\text { mengajar dan menyimpan data } \\
\text { catatan. }\end{array}$ & Berhasil \\
\hline 11 & $\begin{array}{l}\text { Verifiksi } \\
\text { absen }\end{array}$ & $\begin{array}{l}\text { Pilih matakuliah yang sedang } \\
\text { berlangsung pada android } \\
\text { dosen setelah melakukan } \\
\text { presensi, maka akan tampil } \\
\text { kode } Q R \text { dan mahasiswa } \\
\text { melakukan scan paraf. }\end{array}$ & $\begin{array}{l}\text { Menampilkan kode } Q R \text { untuk } \\
\text { mahasiswa melakukan scan paraf di } \\
\text { akhir perkuliahan. }\end{array}$ & Berhasil \\
\hline
\end{tabular}

Pada proses awal user melakukan login untuk masuk pada menu utama, dan kaprodi melakukan monitorin dosen terkait absensi perkuliahan dengan Pilih menu monitoring presensi kemudian pilih nama dosen dan pilih jadwal matakuliah, mastering dosen dan mahasiswa dilakukan oleh administrator untuk menambah ubah dan hapus data mahasiswa dan dosen apabila ada perubahan data, krs mahasiswa dilakukan oleh admin apabila ada mahasiswa yang tidak tercantum namanya di jurnal presensi. lihat jadwal dilakukan oleh mahasiswa dan dosen untuk melihat jadwal yang telah diampu. Ganti jadwal dilakukan oleh admin apabila dosen berhalangan hadir, dan mahasiswa dapat melihat jadwal yang telah diganti pada android mahasiswa. Riwayat presensi dilakukan oleh dosen apabila ingin melihat presensi mulai dari pertemuan awal sampai akhir dan mahasiswa apabila ingin melihat riwayar presensinya sendiri. Lihat profil dilakukan oleh mahasiswa dan dosen apabila ingin mengupdate profil dan mahasiswa dapat melihat profil dosen. Jurnal mengajar dilakukan oleh dosen diakhir perkuliahan dengan mengisi form jurnal menajar dan menyimpannya. Verifikasi absensi dilakukan oleh dosen untuk menampilkan kode $Q R$ untuk mahasiswa melakukan konfirmasi absensi untuk menyatakan bahwa dosen telah melakukan blajar menajar didalam kelas.

2. User acceptance test merupakan proses pengujian oleh user dan menghasilkan dokumen untuk dijadikan bukti bahwa sistem yang dikembangkan dapat diterima oleh user dan hasil pengujianya dianggap memenuhi kebutuhan pengguna ([1]). Pengujian user acceptance test diperoleh 200 responden yaitu mahasiswa dan dosen di Fakultas Sains dan Teknologi.

\section{E. Implementasi}

Implementasi dalam penelitian ini dilakukan dengan diujikan langsung kepada pengguna. oleh mahasiswa, dosen didalam kelas dan administrator Fakultas Sains dan Teknologi. 


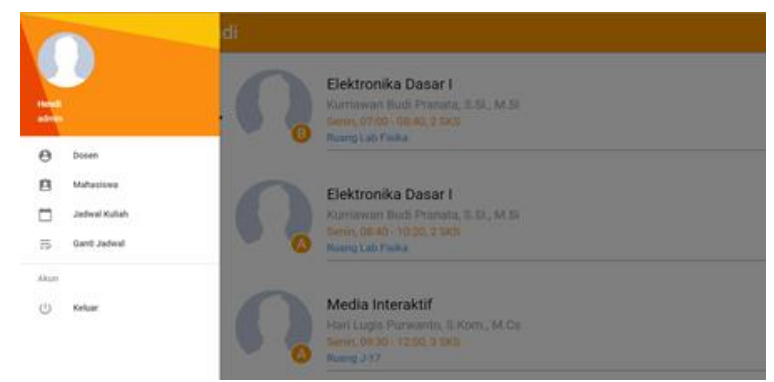

Gambar 10 Mastering Dosen

Fungsi dari mastering dosen ini, Admin dapat melihat data dosen dan dapat melakukan tambah, update, hapus data dosen kemudian menyimpanya. Dapat dilihat pada gambar 10.

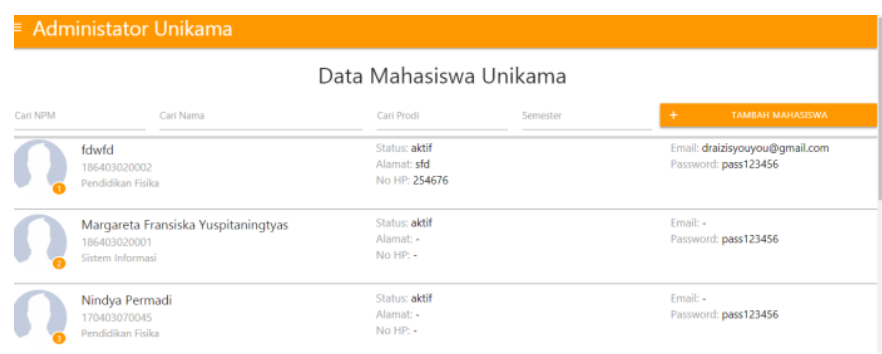

\section{Gambar 11 Mastering Mahasiswa}

Fungsi dari mastering Mahasiswa ini, Admin dapat melihat data mahasiswa dan dapat melakukan tambah, update, hapus data mahasiswa kemudian menyimpanya. Dapat dilihat pada gambar 11.

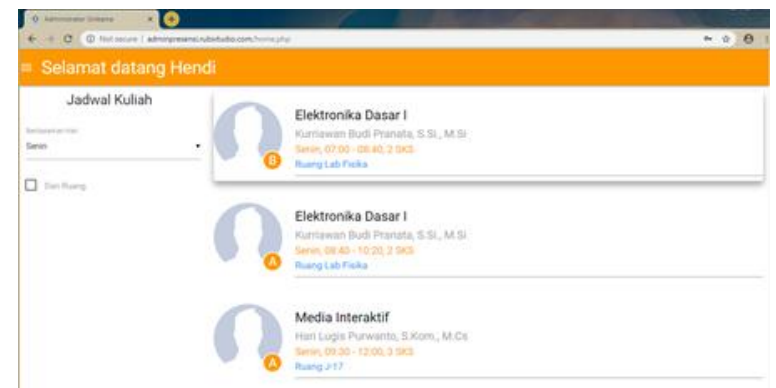

\section{Gambar 12 Halaman Ganti Jadwal}

Fungsi dari ganti jadwal ini, admin pilih matakuliah atau dapat memilih berdasarkan hari atau ruang setelah itu admin mengisi form ganti jadwal lalu simpan. dapat dilihat pada gambar 12.

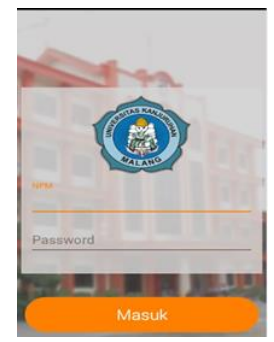

\section{Gambar 13 login Android mahasiswa dan dosen}

Fungsi login ini dilakukan oleh mahasiswa dan dosen pada Android masing - masing, dengan input username dan password kemudian akan divalidasi oleh sistem jika benar maka akan masuk ke menu utama. Dapat dilihat pada gambar 13. 


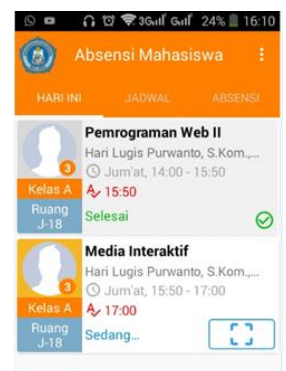

\section{Gambar 14 Jadwal Matakuliah}

Fungsi dari jadwal matakuliah yang sedang berlangsung ini, mahasiswa dan dosen dapat membuka scan presensi untuk absensi perkuliahan. Dapat dilihat pada gambar 14.

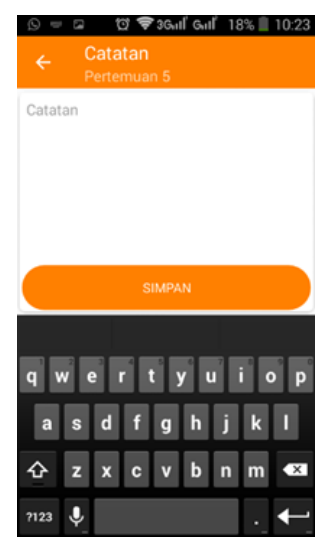

Gambar 15 jurnal mengajar

Fungsi jurnal menajar ini, dosen dapat melakukan pengisi jrnal mengajar di akhir perkuliahan dengan isi form jurnal mengajar setalah selesai maka simpan catatan. Dapat dilihat pada gamabar 15 .

\section{a. Hasil uji coba}

Berdasar kan hasil uji user acceptance test dari 200 responden terdapat total huruf A yang dipilih sebanyak 1259, huruf B sebanyak 1156, huruf C sebanyak 528, huruf D sebanyak 51, huruf E sebanyak 6 responden. Kemudian dilakukan perhitungan dengan hasil prosentase yang didapatkan $83 \%$. Dapat disimpulkan bahwa responden mendukung dengan adanya sistem presensi perkuliahan menggunakan Qrcode untuk dikembangkan dan digunakan pada saat perkuliahan berlangsung.

\section{PENUTUP}

Sistem presensi perkuliahan dapat dibangun menggunakan metode waterfall yang menghasilkan login, monitoring presensi, mastering dosen, mastering mahasiswa, krs mahasiswa, lihat jadwal, ganti jadwal, riwayat presensi, lihat profil, jurnal mengajar, verifikasi absen.

Pada sistem ini mahasiswa dapat melihat jadwal perkuliahan, melihat riwayat absensi sendiri dan dapat melakukan update profil. Sedangkan bagi dosen mempermudah dalam mengawasi mahasiswa terkait kehadiran didalam kelas, mengetahui siapa yang terlambat dan izin keluar kelas, mencegah penitipan absen bagi mahasiswa dan mencegah rekap absen dosen, dapat mengganti jadwal perkuliahan (apabila ada halangan tidak bisa mengajar). Presensi perkuliahan dilakukan berdasarkan jadwal kuliah dan jam yang sudah ditentukan, jika mahasiswa atau dosen melakukan keterlambatan maka sistem akan memberitahu dengan menampilkan "maaf anda terlambat", secara otomatis tidak dapat melakukan scan Qrcode..Berdasarkan hasil uji black box dan user acceptance test yang dilakukan kepada mahasiswa dan dosen hasilnya fungsi pada sistem dapat berjalan dengan baik dan hasil UAT 
mencapai $83 \%$. Sehingga dapat dinyatakan dengan adanya sistem presensi perkuliahan mempermudah dosen dan mahasiswa pada saat melakukan absensi.

\section{DAFTAR PUSTAKA}

Kadir, Abdul. 2015. Rekayasa Web. Yogyakarta: Andi Offset.

Nuddin, Mukhamad Taqwa; Fithri, Diana Laily. 2015. Sistem Absensi Asisten Dosen Menggunakan QR Code Scanner Berbasis Android Pada Program Studi Sistem Informasi Universitas Muria Kudus. Fakultas Teknik, Universitas Muria Kudus ISBN:978-602-1180-21.

Sholeh, Moh. Lukman; Muharom, Lutfi Ali. 2016. Smart presensi menggunakan Qrcode dengan enkripsi vigenere Cipher. J.Math.and Its Appl, Fakultas Teknik, Universitas Muhammadiyah Jember. ISSN:1829-605X Vol.13, No.2.

Zuriyadi, Ridwan Fridh; Hariyono, Santoso; , Agung Wiseto P. 2010. Mengamankan Single Identity Number (SIN) Menggunakan QR Code dan Sidik Jari. 2 (2): 17-20. 